\title{
The Anti-Carcinogenic Effect of Indole-3-Carbinol and 3, 3'-Diindolylmethane and their Mechanism of Action
}

\section{Fuad Fares*}

University of Haifa and Department of Molecular genetics, Carmel Medical Center, Haifa, Israel

\begin{abstract}
Indoles are aromatic heterocyclic organic compound and became the precursor to many pharmaceuticals. Indoles are found naturally in cruciferous plants and indole derivatives, indole-3-carbinole (I3C) and 3, 3'-diindolylmethane (DIM) can also be synthesized by a variety of methods. In vitro studies indicated that I3C and DIM inhibit cell proliferation, caused cell cycle arrest at G1 phase and induced apoptosis. The precise molecular mechanisms by which indole derivatives exert their tumor suppressive effects in human cancer cells are still unclear. It was reported that indoles alter estrogen metabolism. Microarray gene expression profiling and other studies indicated that indoles regulate many genes that are important for the control of cell cycle, cell proliferation, apoptosis, signal transduction, angiogenesis and cell invasion. In addition, it was found that indoles prevent tumor formation of breast and prostate cancer in animal models. Furthermore, these derivatives were evaluated in human clinical trials phase I and phase II as a potential chemopreventive agents against human breast, ovary, and vulvar intraepithelial neoplasia and colon cancers. Preliminary findings of these studies showed a significant clinical improvement. Interestingly, the use of indole derivatives was found to be safe without any indicated side effects. In conclusion, the results provide an evidence of the benefit of indole-derivatives in the prevention and treatment of hormone-dependent and hormone-independent human cancer. Further clinical trials are needed in order to approve the efficacy of indole derivatives in treatment of human cancer and to evaluate the indole use by the Food and Drug Administration (FDA).
\end{abstract}

Keywords: Glucosinolates; Indole-3-carbinol;3,3'-diindolylmethane; Cancer treatment; Cancer prevention

\begin{abstract}
Abbreviations: DIM: 3:3'-Diindolylmethane; I3C: Indole3-Carbinol; CDK6: Cyclin-Dependent Kinase 6; $\mathrm{NF}_{-\mathrm{k}} \mathrm{B}$ : Nuclear Factor $_{\mathrm{k}} \mathrm{B}$; ROS: Reactive Oxygen Species; PI3-K/Akt: Phosphatidylinositol 3-Kinase; JNK: C-Jun NH(2)-Terminal Kinase; DMBA: Dimethylbenz(A)Anthracene; BP: Benzo(A)Pyrene; DEN: Diethylnitrosamine; ER: Endoplasmic Reticulum; CYP: Cytochrome P450; DHT: Dihydrotestosterone; PARP: Poly(ADP-Ribose) Polymerase; TFDP: Transcription Factor Dp; CBFB: Core Binding Factor Beta; STI6: Suppressor of Tumorigenecity; EGFR: Epidermal Growth Factor Receptor; AR: Androgen Receptor; HPV: Human Papilloma Virus; TRAIL: Tumor Necrosis Factor-Related ApoptosisInducing Ligand
\end{abstract}

\section{Introduction}

Epidemiological studies show that increased consumption of cruciferous vegetables such as cabbage, brussels sprouts, broccoli and cauliflower, is associated with decreased incidence of human cancer. The protective effect of cruciferous vegetables includes colon cancer [1-3], gastric cancer [4], breast [5-7], thyroid [8], mesothelioma [9] and prostatic cancer [10]. In addition to the epidemiological data, experimental animal studies have been carried out in order to confirm the protective effect of cruciferous vegetables in retarding the development of chemically induced human hepatic or mammary tumorigenesis [11-15].

The anticarcinogenic effects of indole-diet derivatives in experimental animal models and in humans raise the special attention of these compounds as possible chemopreventive agents. Here we summarized the data regarding the inhibitory effects of indole derivatives on human cancer and provide the possible molecular mechanisms of these compounds in the treatment and prevention of human cancer.

\section{Indole Compounds}

Cruciferous vegetables contain large amounts of glucosinolates, such as glucobrassicin and neoglucobrassicin [16,17]. Glucobrassicin in cruciferous vegetables undergoes hydrolysis by the enzyme myrosinase, and the main product of this hydrolysis is 3-indolylmethyl glucobrassicin. When a vegetable is cut or chewed, 3-indolylmethyl glucobrassicin is hydrolyzed to form indole-3-carbinol (I3C) [18] (Figure 1). In an acidic environment and low $\mathrm{pH}, \mathrm{I} 3 \mathrm{C}$ may condense into other polymeric products were 3,3'-diindolylmethane (DIM) and ascorbigene are the main products (Figure 2). In order to study the in vivo disposition of $\mathrm{I} 3 \mathrm{C}$, rainbow trout was fed with radiolabeled [5- ${ }^{3} \mathrm{H}$ ]-indole-3-carbinol. After 48 hours, $40 \%$ of total radioactivity was found in the liver extracts as DIM [19]. When I3C was incubated in a simulated gastric condition, it was found that the reaction mixture contained over 20 products were DIM was found to be about $10-20 \%$ and $\mathrm{I} 3 \mathrm{C}$ was found only $0.5 \%$ of total products [20]. In vivo studies using rats showed that DIM was detected in gastric contents, stomach tissue, small intestine and liver after one hour of receiving oral dose of I3C [21].

\section{The Anti-Cancer Effect of Indole-Diet Derivatives}

\section{The effect of indole derivatives on breast cancer}

Breast cancer is the most common malignancy diagnosed in women in Western countries. It is well known that elevated levels of estradiol-17 $\beta$ activity and presence of a functional estrogen receptor

*Corresponding author: Fuad Fares, Department of Human Biology, Faculty of Natural Sciences, University of Haifa, Mount Carmel, Haifa31095, Israel, Tel: 972-4-8288781; Fax: 972-4-8288763; E-mail: ffares@sci.haifa.ac.il

Received February 17, 2014; Accepted March 20, 2014; Published March 22, 2014

Citation: Fares F (2014) The Anti-Carcinogenic Effect of Indole-3-Carbino and 3, 3'-Diindolylmethane and their Mechanism of Action. Med chem S1: 002 doi:10.4172/2161-0444.S1-002

Copyright: (c) 2014 Fares F. This is an open-access article distributed under the terms of the Creative Commons Attribution License, which permits unrestricted use, distribution, and reproduction in any medium, provided the original author and source are credited. 


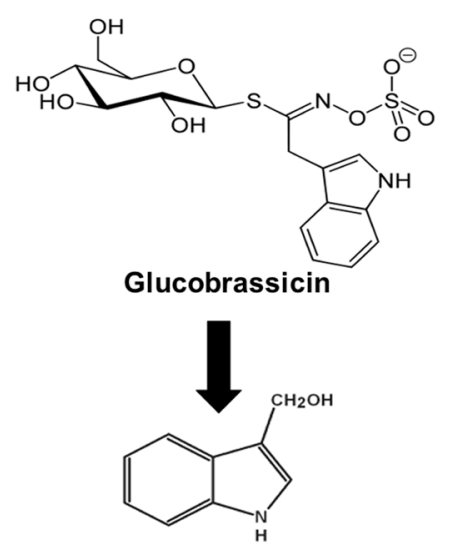

Indole-3-carbinol

Figure 1: Molecular structure and metabolism of I3C.

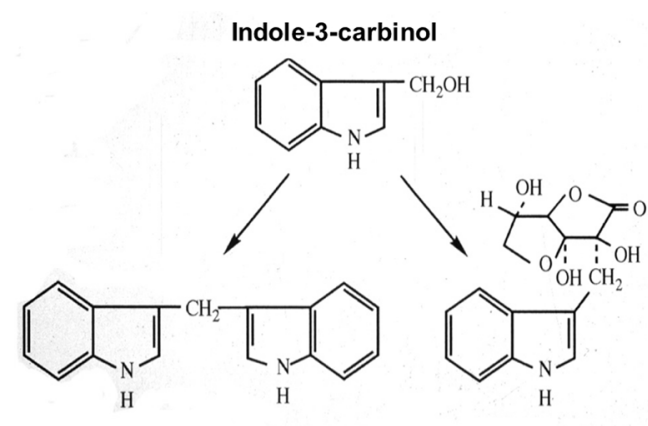

3,3-diindolylmethane

Ascorbegin

Figure 2: The chemical structure of Indole-3-carbinol, 3,3'-diindolylmethane and ascorbigen.

in human breast tissue increased the risk of breast cancer [22-24]. Reduction in breast cancer risk was often associated with consumption of carrots and green vegetables that are rich in carotenoids. Experimental studies indicated that feeding mice with dried cabbage decreased incidence of pulmonary metastases after intravenous injection with mammary tumor cells [25]. Moreover, it was found that consumption of cruciferous vegetables increases the ratio of 2-hydroxyestrone to 16- $\alpha$-hydroxyestrone, the oxidative product of 16- $\alpha$-hydroxyestradiol-17 $\beta$, and reduces the incidence of breast cancer in women [26,27]. Experimental studies in vitro indicated that I3C, DIM as well as cabbage juices affect the expression of CYP1 family genes encoding the key enzymes of estrogen synthesis [28,29]. Other studies indicated that indole derivatives are significantly reduced the expression of estrogen alpha-receptor in human breast cancer cells [30-32]. Several studies have examined the effects on I3C and its metabolites on growth of human cancer cells lines including breast [3337]. I3C and DIM suppressed the growth of human breast cancer cells of estrogen receptor positive and estrogen receptor negative. In the molecular mechanism it was found that $\mathrm{I} 3 \mathrm{C}$ inhibited cyclin-dependent kinase 6 (CDK6), induced p27 expression and reduced the level of retinoblastoma protein. Other studies indicated that $\mathrm{I} 3 \mathrm{C}$ also induced cell cycle arrest in breast cancer cells and inhibited CdK6, but in high concentration of $200 \mu \mathrm{M}$ [37-39]. In addition, it was demonstrated that I3C activates p53 phosphorylation and disruption of the p53-MDM2 interaction, which releases p53 to induce the p21 CDK inhibition and
G1 cell cycle arrest $[30,40]$. These studies suggested that I3C induced phosphorylation of phosphatidyl-inositol-3-kinase (PI3-K/Akt) family member, ataxia telangiectasia gene that activates p53 through its phosphorelation that induce $\mathrm{p} 21^{\mathrm{WAF} 1} \mathrm{CDK}$ inhibitor and caused a G1 cell cycle arrest. Moreover, studies from different laboratories have shown that indole derivatives are potent inducers of apoptosis in breast cancer cells [34-43]. DIM induced apoptosis in human breast cancer cells through inactivation of PI3-K/Akt and nuclear factor-kB (NF- $\mathrm{B})$ pathways [43]. PI3-K/Akt signaling pathway is an important signal transduction pathway in cells and plays a critical role in controlling cell survival and apoptosis. It was reported that PI3-K/Akt regulates the NF- $\mathrm{B}$ activation directly through activation of IkB kinase (IKK) or phosphorylation of RelA [44]. On the other hand, $\mathrm{NF}_{\mathrm{k}} \mathrm{B}$ is a key regulator of genes involved in cell activation and proliferation [45-47]. Therefore, $\mathrm{NF}_{-\mathrm{k}} \mathrm{B}$ has been described as a major therapeutic target in cancer where inhibition of its activities generally believed to suppress tumorigenesis and the progression of tumors. Furthermore, it was shown that $\mathrm{I} 3 \mathrm{C}$ induced BRCA1 and BRCA2 expression and that both I3C and BRCA1 inhibit estrogen-stimulated estrogen receptor alpha activity in human breast cancer [48]. BRCA1 and BRCA2 have been identified as tumor suppressors for several different hormone responsive cancer types including breast cancer. BRCA1 expression is decreased or absent in a significant proportion of sporadic breast cancer because of hypermethylation of the gene promoter [49,50].

Other studies indicated that I3C down regulated epidermal growth factor receptor (EGFR) in human breast cancer cell lines and induce cell cycle arrest and apoptosis [51,52]. In addition, it was shown that DIM treatment induced hyperpolarization of mitochondrial inner membrane, decreased cellular ATP level, and significantly stimulated mitochondrial reactive oxygen species (ROS) production. ROS production, in turn, led to the activation of stress-activated pathways involving p38 and c-Jun $\mathrm{NH}(2)$-terminal kinase (JNK). Using specific kinase inhibitors (SB203580 and SP600125), it was shown that the central role of p38 and JNK in cells where DIM-induced p21 $1^{\mathrm{WAF} 1}$, is in the transcription level. In addition, antioxidants significantly attenuated DIM-induced activation of p38 and JNK and induction of $\mathrm{p} 21$, indicating that oxidative stress is the major trigger of these events [53].

The role of indole-diet derivatives in breast cancer prevention and treatment was examined in animal models. Mice fed with dried cabbage showed a decreased incidence of pulmonary metastases after intravenous injection of mammary tumor cells [54] and reduced the incidence of spontaneous estrogen-responsive tumors such as mammary [55]. On the other hand, diet containing cabbage significantly lower incidence of mammary cancer induced by $\mathrm{N}$-methyl- $\mathrm{N}$-nitrosourea in female Sprague-Dawley rats [15]. In addition, it was reported that the oral administration of female Sprague-Dawley rats with DIM or I3C before administration of the carcinogens; dimethylbenz(a)anthracene (DMBA) that induced mammary tumor formation or benzo(a)pyrene (BP) that induced neoplasia of the forestomach, significantly inhibited tumor formation [56,57]. Other study in our laboratory indicated that ascorbigen was found to have the ability to inhibit the formation of DMBA-initiated mammary tumors in female Sprague-Dawley rats (Unpublished data).

However, in vitro studies using human breast cancer cells suggest possible modes of indole derivatives activity. However, little is known regarding the in vivo mechanism of action where indoles inhibit mammary tumor growth. One interesting possibility that have been received attention is the ability of DIM to inhibit angiogenesis. The results indicated that DIM strongly inhibited proliferation, migration, 
invasion and capillary tube formation in cultured human umbilical vein endothelial cells. In a complementary in vivo Matrigel plug angiogenesis assay it was observed that treatment of $5 \mathrm{mg} / \mathrm{kg}$ of DIM inhibited neovascularization by $76 \%$ compared to untreated animals. In addition this dose of DIM also inhibited the growth of human MCF-7 cell tumor xenografts by up to $64 \%$ in female athymic mice. Interestingly, these studies did not observe any weight loss or toxicity to major organs of the animal $[57,58]$. Other study indicated that I3C suppressed the capillary-like tube formation by phorbol myristate acetate-stimulated endothelial EA hy926 cells and such inhibition was associated with decreased vascular endothelial growth factor and its receptor [59]. In addition, extracts of broccoli suppressed 12-O-tetradecanoylphorbol-13-acetate-induced cancer cell invasion and matrix metallopropeinase- 9 activity and therefore suppressed the invasiveness of human breast cancer cells in vitro [60].

\section{The effect of indole derivatives on prostate cancer}

Prostate cancer is the most common diagnosed malignancy (accounting for $29 \%$ of the newly diagnosed cancers) and the second leading cause of male death in Western industrialized countries [61]. Age, race, and family history are known risk factors for this disease. However, recently it has been found that nutritional and hormonal risk factors are also involved in prostate cancer [62]. Mortality from prostate cancer results from metastases to the bones and lymph nodes and progression from androgen-dependent to androgen-independent prostatic growth [63]. Androgen withdrawal causes involution of the prostate gland, as a result of inhibition of cellular proliferation and stimulation of apoptosis of the androgen-dependent cells. Although androgen withdrawal remains the only effective therapy for men with advanced disease, in approximately $80 \%$ of the patients, progression to the lethal and untreatable stage of androgen-independence eventually occurs. The increasing incidence of prostate cancer in men all over the world, has led to the performance of intense investigations, searching for compounds having efficient anti-carcinogenic effects against this type of cancer. These studies examined mainly apoptotic properties of the compounds investigated on human prostate cancer cells, under in vitro and in vivo conditions. The results indicated that I3C and DIM suppress the growth of human prostate cancer cells in a dose- and timedependent manner [64-70]. DIM exhibited potent antiproliferative and antiandrogenic properties in androgen-dependent human prostate cancer cells. As a part of the antiproliferative mechanism of I3C in human prostate cancer, it was found that $\mathrm{I} 3 \mathrm{C}$ represses the expression of androgen receptor [71,72]. DIM suppresses cell proliferation of androgen-dependent, cells, LNCaP, and inhibits dihydrotestosterone (DHT) stimulation of DNA synthesis. These effects were not found in androgen-independent PC-3 cells. Interestingly, results of receptor binding assays indicated that DIM is a strong competitive inhibitor of DHT binding to androgen receptor [72]. Moreover, DIM inhibited endogenous PSA transcription and reduced intracellular and secreted PSA protein levels induced by DHT in LNCaP cells [73]. In addition, the growth inhibition of prostate cancer cells by I3C or DIM found to be through cell-cycle arrest at G1 checkpoint [64,74-76]. I3C inhibited the expression of CDK6 and upregulated the expression of $\mathrm{p} 21^{\mathrm{WAF} 1}$ and $\mathrm{p} 27^{\mathrm{K} 1 \mathrm{P1}}$ in well differentiated (LNCaP) and poorly differentiated (PC3) cells suggesting the inhibition of cell-cycle progression [77]. Furthermore, I3C and DIM induced apoptosis in human prostate cancer cells. We provided evidence that the induction of apoptosis in human prostate cancer cells by DIM is exerted through the mitochondrial pathway [78]. DIM triggers cytochrome $\mathrm{C}$ translocation from the mitochondria to the cytosol that promotes the activation of caspase 9 that activate effector caspases; 3 and 6 in a time-dependent manner. The activation of these effectors leads to the cleavage of poly (ADP-ribose) polymarase (PARP), an enzyme implicated in DNA damage and repair mechanisms. Other studies indicated that I3C decreases the expression of $\mathrm{Bcl}-2$ and $\mathrm{Bcl}_{\mathrm{xL}}$ genes that inhibit apoptosis, and upregulated Bax gene which induced apoptosis $[65,78]$ Translocation of Bax from cytosol to the mitochondria, causing the mitochondrial permeability transition, loss of mitochondrial potential, release of cytochrome $\mathrm{C}$, activation of caspases followed by cleavage of PARP and inducing DNA fragmentation and thus inducing apoptosis [78]. It was reported that I3C significantly inhibited $\mathrm{NF}_{k} \mathrm{~B}$ DNA binding in PC3 cells and thus inhibition of cell proliferation together with induction of apoptosis $[64,79]$. In addition, it was found that I3C and DIM downregulated the expression of Pol II transcription factor $\mathrm{Dp}$ (TFDP), the nuclear factor YC (NF-YC) and the core binding factor beta (CBFB) that play an important role in transcription, cell-cycle progression and oncogenesis [80]. On the other hand, these derivatives upregulated the expression of the suppressor tumorigenicity 16 (ST16) [81]. It was reported also that indole derivatives inhibited epidermal growth factor receptor (EGFR) expression, PI3K/Akt activation and abrogated the EGF-induced activation of PI3K/Akt in prostate cancer cells [82-84]. PI3K/Akt signal transduction pathway plays a critical role in controlling the balance between cell survival and apoptosis in human cancer cells [84]. Other study indicated that I3C increased the expression of two tumor necrosis factor-related apoptosis-inducing ligand (TRAIL) death receptors (DR4 and DR5). Treatment of LNCaP cells with I3C induced DR4 and DR5 expression at both transcriptional and translational levels [85]. It was also reported that DIM could activate the AMPK signaling pathway, associated with suppression of the mammalian target of rapamycin (mTOR), down-regulation of androgen receptor (AR) expression, and induction of apoptosis in both androgen-sensitive $\mathrm{LNCaP}$ and androgen-insensitive $\mathrm{C} 4-2 \mathrm{~B}$ prostate cancer cells. DIM also activates AMP-protein kinase (AMPK) and down-regulates $\mathrm{AR}$ in androgen-independent $\mathrm{C} 4-2 \mathrm{~B}$ prostate tumor xenografts in SCID mice. These results suggest that DIM could be used as a potential anti-cancer agent in the clinic for prevention and/ or treatment of prostate cancer regardless of androgen responsiveness, although functional AR may be required [86].

The global gene expression profiles of prostate cancer cells following I3C or DIM treatment were not clear. To obtain comprehensive gene expression profile of indole derivatives in human prostate cancer, cDNA microarray was utilized. A total of 738 genes that showed a greater than two fold change were detected after $24 \mathrm{~h}$ of treatment with DIM. Among these genes, 677 genes were down regulated and 61 were upregulated [47]. It was concluded that I3C and DIM affected the expression of a large number of genes that are related to the control of carcinogenesis, cell survival and physiologic behaviors. These results may lead to determine the molecular mechanism by which indole derivatives exert their anticarinogenic effect in human prostate cancer cells.

The in vivo activity of DIM was investigated by us using male C57BL/6 mice in which tumors were initiated by subcutaneous transplantation of TRAMP-C2 cells derived from a primary tumor of the C57BL/6 prostate. The results indicated that treatment with DIM ( $2.5 \mathrm{mg}, 5 \mathrm{mg}$ or $10 \mathrm{mg} / \mathrm{kg}$ ) 3 times a week for 3 weeks, significantly diminished tumor growth. Histological examination of tumor sections revealed that DIM decreased cell proliferation as it was detected by the anti-mouse $\mathrm{Ki}-67$ staining. Ki-67 is a nuclear protein expressed during all active phases of cell cycle. Moreover, it was found that DIM induced apoptosis in the tumor cells as it was detected by DAPI staining. DAPI is a fluorescence compound that specifically binds to DNA and allows visualization of its morphology. Treatment with DIM had no effect 
on body weight or kidney and liver functioning [77]. Other study examined the effect of I3C on prostate cancer model using Copenhagen rats and the transplantable cell line, MAT-LyLu, a cell line derived from a prostate tumor of Copenhagen rats and it is androgen independent and metastasizes to the lung and lymph nodes. The results indicated that I3C inhibited the incidence, growth and metastases of MAT-LyLu cells [76]. Using the same animal model it was found that fed male Copenhagen rats with diets containing $10 \%$ broccoli, decreased tumor weight by $42 \%$. Tumor growth reduction was associated with reduced proliferation and increased apoptosis [87]. Moreover, treatment of mice with DIM inhibits tumor formation of TRAMP cells, mouse prostate cancer cells [88].

These results indicated that indolic compounds, I3C and DIM, may constitute important anti-carcinogenic and therapeutic food derivatives against human prostate cancer offering natural compounds with minimal toxic effects in the treatment and prevention of human prostate cancer.

\section{The effect of indole derivatives on other types of cancer}

Dietary indoles has been documented as inhibiting tumorigenesis in various target organs including colon [89-91], thyroid [92], pancreas [93], liver [94], cervix [95,96], melanoma [97], and lung [98,99].

In vitro studies indicated that DIM substantially decreased the number of viable cells and induced apoptosis of the human colorectal cancer cell lines; HCT116, well differentiated with p53 wild-type, and HT-29, moderately differentiated with p53 mutant, in a concentrationdependent manner [100]. This effect was mediated through the increase of the translocation of cytochrome $\mathrm{C}$ from the mitochondria to the cytoplasm. This was followed by the activation of caspases and the activation of PARP cleavage without affecting the protein levels of p53, Bax or Fas ligand but it decreased the protein level of Bcl-2. Other study indicated that DIM and I3C induce apoptosis in human colorectal cancer cells; LS-174, Caco-2 and HCEC. It was also demonstrates that DIM stimulates activating transcription factor 3 (ATF3) expression through ATF4-mediated pathway and subsequently induces apoptosis in human colon cancer cells [101]. In experimental animal model it was shown that cruciferous vegetables inhibited chemically induced colon cancer [102].

The anti-thyroid cancer activity of I3C and DIM were studied using different thyroid cancer cell lines representative of papillary (B-CPAP and $8505-\mathrm{C}$ cells) and Follicular (CGTH-W-1 and ML-1) carcinoma of the thyroid. These studies indicated that DIM is more potent than I3C in inhibiting cell survival of both papillary and follicular thyroid carcinoma cells. The anti-proliferative effect of DIM was mediated by G1 arrest followed by induction of apoptosis. Interestingly, DIM also inhibited the growth of primary thyroid goiter cells by $70 \%$ [91]. These studies provide a strong rational for the clinical exploration of DIM as an adjuvant to surgery in thyroid proliferation diseases.

Human papilloma virus (HPV) is an important risk factor for cervical cancer [103]. Transgenic mice that express cancerpromoting HPV genes develop cervical cancer following treatment with $17 \beta$-estradiol. Using this model it was shown that feeding the transgenic animals with $\mathrm{I} 3 \mathrm{C}$ significantly reduced the number of mice that developed cervical cancer [104].

The hepatic tumor-modulatory properties of I3C fed to C57BL/6 mice initiated with diethylnitrosamine (DEN) were studied. The results indicated that long-term administration of I3C in the diet inhibits DEN-initiated hepatocarcinogenesis in the infant mouse model [93].
Because I3C was known to induce estradiol 2-hydroxylase and reduce estrogen activity, the possible inhibiting effect of $\mathrm{I} 3 \mathrm{C}$ on spontaneous occurrence of endometrial adenocarcinoma in female Donryn rats was examined. In this strain of rats, the related estrogen/ progesterone ratio is increasing with age and the high incidence of endometrial cancer is detected. The results indicated that the incidences of endometrial adenocarcinoma in rats fed I3C were significantly smaller than that detected in the control group. These results suggested that dietary I3C inhibits spontaneous occurrence of endometrial adenocarcinoma, an effect that may be due to the induction of estradiol 2-hydroxylation [105].

DIM and its derivatives inhibited the growth and induce apoptosis of human pancreatic cells in vitro. The decrease in cell proliferation was accompanied by increased indoplasmic reticulum (ER) staining and calcium release. This was accompanied by increased expression of glucose related protein 78 and C/EBP homologous transcription factor (CHOP/GADD153) proteins showing induction of ER stress leads to activation of the apoptotic pathway [92]. This study indicated also that DIM increase the expression of the TRAIL death receptor, DR5. Therefore, two molecular mechanistic pathways of DIM were suggested in human pancreatic cancer cells; activation DR5, receptor-dependent pathway, and inducing ER stress, receptor independent pathway. DNA microarray studies using transformed keratinocytes and tumor cell lines suggested that cellular mRNA content from genes associated with ER stress response (GADD153, ATF3, EBP- $\beta$ ) was increases within 4-6 hours of exposure to pharmaceutical concentrations of DIM [106]. Other studies using human breast and prostate cancer cell lines support the hypothesis that cytotoxic concentrations of DIM can activate cellular stress response pathways in vitro including the ER stress response. Other major stress-associated genes were also upregulated by DIM, such as; GADD153, GADD45A, ATF4, GADD34, GRP78, GRP94' XBP-1 and asparagines synthase [107]. It was also reported that $\mathrm{I} 3 \mathrm{C}$ exhibited the highest potency in radical scavenging activity and was most protective against oxidative stress in neuronal cell assays [108].

\section{Human Clinical Studies}

The use of vegetables for hundreds of years, the hundreds of carefully observed animal studies, and the consumption of synthetic I3C by thousands of people without noticeable harmful effects have shown that I3C is a safe dietary supplement. Therefore, Indole-diet derivatives were found to be safe compounds and they were evaluated in human clinical trials as potential chemopreventive agents. In phase I trial of I3C, 17 women from a high-risk breast cancer were used [109]. The results indicated that daily administration of I3C at doses of 400 and $800 \mathrm{mg}$ was well tolerated by all subjects. These dose levels produced significant changes in the activities of at least two xenobiotic and steroid-metabolizing enzymes and markedly altered the ratio of hydroxylated estrone metabolites in a manner consistent with chemoprevention. The use of $400 \mathrm{mg}$ of I3C daily seems to be safe and effective supplement for women $[106,107,109,110]$. Other study indicated that DIM supplementation at a dose of $108 \mathrm{mg} /$ day for 30 days increased urinary 2-hydroxyestrone excretions in postmenopausal women with a history of breast cancer [110].

Other report of phase II study determined the potential therapeutic benefits of I3C in the management of vulvar intraepithelial neoplasia [111]. Preliminary findings of this study showed a significant clinical improvement in symptomatology and vulvoscopic appearance of vulvar intraepithelial neoplasia with I3C therapy. 
The effect of $\mathrm{I} 3 \mathrm{C}$ on the progression of cervical cancer in women was examined. It was found that four of eight women, who took 200 $\mathrm{mg} /$ day of I3C for 12 weeks, had complete regression of the tumor, while none of the ten who took a placebo had complete regression [112].

The therapeutic benefits of indole-3-carbinol (I3C) in the management of vulvar intraepithelial neoplasia (VIN) was reported. Women with histologically confirmed high-grade VIN were randomized to receive 200 and $400 \mathrm{mg}$ /day of I3C. This study has shown significant clinical improvement in symptomatology and vulvoscopic appearance of VIN with I3C therapy. Further clinical and scientific investigations are required to support these preliminary findings [111].

These results are similar to that found in animal studies where I3C and DIM exhibited a profound chemopreventive effect. Although the preliminary results seem to be promising, large controlled clinical trials are needed in order to determine the efficacy of the indole derivatives on the preventing the progression of human cancer.

\section{Safety}

Sixty women at increased risk for breast cancer were enrolled in a placebo-controlled, double blind dose-ranging chemoprevention study of I3C. Fifty-seven of these women with a mean age of 47 years range [21-72] completed the study. Each woman took a placebo capsule or an I3C capsule daily for a total of 4 weeks. None of the women experienced any significant toxicity effects. However slight increases in the serum concentrations of a liver enzyme (alanine aminotransferase; ALT) were observed in two women who took unspecified doses of I3C supplements for four weeks [113]. Other study indicated that one person reported a skin rash while taking $375 \mathrm{mg} /$ day of I3C [114]. On the other hand high doses of I3C $(800 \mathrm{mg} /$ day $)$ were associated with symptoms of disequilibrium and tremor, which resolved when the dose was decreased [115].

No drug interactions in humans have been reported. However, preliminary evidence that $\mathrm{I} 3 \mathrm{C}$ and DIM can increase the activity of CYP1A2 [116,117] suggests the potential for I3C or DIM supplementation to decrease serum concentrations of medications metabolized by CYP1A2. Both I3C and DIM modestly increase the activity of CYP3A4 in rats when administered chronically [66]. This observation raises the potential for adverse drug interactions between in humans since CYP3A4 is involved in the metabolism of approximately $60 \%$ of therapeutic drugs.

The safety of I3C or DIM supplements during pregnancy or lactation has not been established.

\section{Conclusions}

These studies prove evidence that the diet-derived indole derivatives, I3C and DIM, exert anticancer effects mediated through the regulation of cell cycle, induction of apoptosis, transcription, cell signal transduction, inhibiting angiogenesis and suppressing cell invasion (Figure 3). The activation of the mitochondrial pathway through releasing of cytochrome $\mathrm{C}$ and activation of caspases, together with inactivation of hormonal, PI3K/Akt, MAPK, Bcl-2 and NF- $\mathrm{B}$ pathways may represent the possible molecular mechanism of indolederivatives in their anticancer activity. The anti-cancer activity of I3C and DIM was detected in various target organs including breast, prostate, colon, liver, cervix, endometrium, melanoma and lung using human cancer cell lines or various animal models. Furthermore, these derivatives were evaluated in clinical trials phase I and phase II as a potential chemopreventive agents against breast, ovary and colon

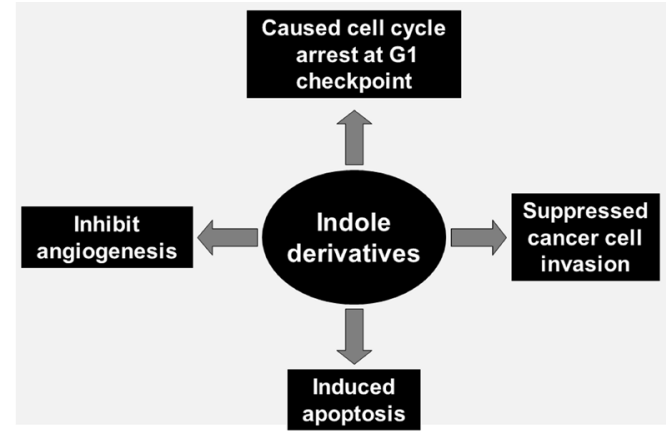

Figure 3: Activities assigned to indole-diet derivatives.

cancers. Preliminary findings of these studies showed a significant clinical improvement. In addition, the use of indole derivatives was found to be safe without any indicated side effects.

\section{References}

1. Graham S (1983) Results of case-control studies of diet and cancer in Buffalo, New York. Cancer Res 43: 2409s-2413s.

2. Benito E, Obrador A, Stiggelbout A, Bosch FX, Mulet M, et al. (1983) A population-based case-control study of colorectal cancer in Majorca. I. Dietary factors. Int J Cancer 45: 69-76.

3. Wohlleb JC, Hunter CF, Blass B, Kadlubar FF, Chu DZ, et al. (1990) Aromatic amine acetyltransferase as a marker for colorectal cancer: environmental and demographic associations. Int J Cancer 46: 22-30.

4. Chyou PH, Nomura AM, Hankin JH, Stemmermann GN (1990) A case-cohort study of diet and stomach cancer. Cancer Res 50: 7501-7504.

5. Graham S, Marshall J, Mettlin C, Rzepka T, Nemoto T, et al. (1982) Diet in the epidemiology of breast cancer. Am J Epidemiol 116: 68-75.

6. Phillips RL (1975) Role of life-style and dietary habits in risk of cancer among seventh-day adventists. Cancer Res 35(11 Pt.

7. Armstrong B, Doll R (1975) Environmental factors and cancer incidence and mortality in different countries, with special reference to dietary practices. Int $\mathrm{J}$ Cancer 15: 617-631.

8. Kolonel LN, Hankin JH, Wilkens LR, Fukunaga FH, Hinds MW (1990) An epidemiologic study of thyroid cancer in Hawaii. Cancer Causes Control 1: 223-234.

9. Schiffman MH, Pickle LW, Fontham E, Zahm SH, Falk R, et al. (1988) Casecontrol study of diet and mesothelioma in Louisiana. Cancer Res 48: 29112915.

10. Correa P (1981) Epidemiological correlations between diet and cancer frequency. Cancer Res 41: 3685-3690.

11. Le Marchand L, Hankin JH, Kolonel LN, Wilkens LR (1991) Vegetable and fruit consumption in relation to prostate cancer risk in Hawaii: a reevaluation of the effect of dietary beta-carotene. Am J Epidemiol 133: 215-219.

12. Stoewsand GS, Babish JB, Wimberly HC (1978) Inhibition of hepatic toxicities from polybrominated biphenyls and aflatoxin $B$ in rats fed cauliflower. J Environ Pathol Toxicol 2: 399-406.

13. Wattenberg LW (1983) Inhibition of neoplasia by minor dietary constituents Cancer Res 43: 2448s-2453s.

14. Wattenberg LW, Hanley AB, Barany G, Sparnins VL, Lam LK, et al. (1985) Inhibition of carcinogenesis by some minor dietary constituents. Princess Takamatsu Symp 16: 193-203.

15. Bresnick E, Birt DF, Wolterman K, Wheeler M, Markin RS (1990) Reduction in mammary tumorigenesis in the rat by cabbage and cabbage residue. Carcinogenesis 11: 1159-1163.

16. McDanell R, McLean AE, Hanley AB, Heaney RK, Fenwick GR (1988) Chemical and biological properties of indole glucosinolates (glucobrassicins): a review. Food Chem Toxicol 26: 59-70. 
17. Kutacek M, Prochazka Z, Veres K (1962) Biogenesis of glucobrassicin, the in vitro precursor of ascorbigen. Nature 194: 393-394.

18. Grose KR, Bjeldanes LF (1992) Oligomerization of indole-3-carbinol in aqueous acid. Chem Res Toxicol 5: 188-193.

19. Dashwood RH, Fong AT, Arbogast DN, Bjeldanes LF, Hendricks JD, et al. (1994) Anticarcinogenic activity of indole-3-carbinol acid products: ultrasensitive bioassay by trout embryo microinjection. Cancer Res 54: 3617-3619.

20. Baldwin WS, LeBlanc GA (1992) The anti-carcinogenic plant compound indole3 -carbinol differentially modulates P450-mediated steroid hydroxylase activities in mice. Chem Biol Interact 83: 155-169.

21. De Kruif CA, Marsman JW, Venekamp JC, Falke HE, Noordhoek J, et al. (1991) Structure elucidation of acid reaction products of indole-3-carbinol: detection in vivo and enzyme induction in vitro. Chem Biol Interact 80: 303-315.

22. Bradlow HL, Hershcop RJ, Martucci CP, Fishman J (1985) Estradiol 16 alphahydroxylation in the mouse correlates with mammary tumor incidence and presence of murine mammary tumor virus: a possible model for the hormonal etiology of breast cancer in humans. Proc Natl Acad Sci U S A 82: 6295-6299.

23. Bradlow HL, Hershcopf R, Martucci C, Fishman J (1986) 16 alpha-hydroxylation of estradiol: a possible risk marker for breast cancer. Ann N Y Acad Sci 464 138-151.

24. Hershcopf RJ, Bradlow HL, Fishman J (1986) Differential hydroxylations of estrone and estradiol in man. J Clin Endocrinol Metab 62: 170-173.

25. Suto A, Bradlow HL, Wong GY, Osborne MP, Telang NT (1992) Persistent estrogen responsiveness of ras oncogene-transformed mouse mammary epithelial cells. Steroids 57: 262-268.

26. Yannai S, Bradlow HL, Westin J, Richard ED (1994) Consumption of cruciferous vegetable - propable protection against breast cancer. Proc Internat Euro Food Tox 2: 480-484.

27. Michnovicz JJ, Bradlow HL (1990) Induction of estradiol metabolism by dietary indole-3-carbinol in humans. J Natl Cancer Inst 82: 947-949.

28. Szaefer H, Licznerska B, Krajka-KuÅniak V, Bartoszek A, Baer-Dubowska W (2012) Modulation of CYP1A1, CYP1A2 and CYP1B1 expression by cabbage juices and indoles in human breast cell lines. Nutr Cancer 64: 879-888.

29. Licznerska BE, Szaefer H, Murias M, Bartoszek A, Baer-Dubowska W (2013) Modulation of CYP19 expression by cabbage juices and their active components: indole-3-carbinol and 3,3'-diindolylmethene in human breast epithelial cell lines. Eur J Nutr 52: 1483-1492.

30. Marconett CN, Singhal AK, Sundar SN, Firestone GL (2012) Indole-3-carbino disrupts estrogen receptor-alpha dependent expression of insulin-like growth factor-1 receptor and insulin receptor substrate-1 and proliferation of human breast cancer cells. Mol Cell Endocrinol 363: 74-84.

31. Sundar SN, Kerekatte V, Equinozio CN, Doan VB, Bjeldanes LF, et al. (2006) Indole-3-carbinol selectively uncouples expression and activity of estrogen receptor subtypes in human breast cancer cells. Mol Endocrinol 20: 3070-3082.

32. Wang TT, Milner MJ, Milner JA, Kim YS (2006) Estrogen receptor alpha as a target for indole-3-carbinol. J Nutr Biochem 17: 659-664.

33. Brandi G, Paiardini M, Cervasi B, Fiorucci C, Filippone P, et al. (2003) A new indole-3-carbinol tetrameric derivative inhibits cyclin-dependent kinase 6 expression, and induces $\mathrm{G} 1$ cell cycle arrest in both estrogen-dependent and estrogen-independent breast cancer cell lines. Cancer Res 63: 4028-4036.

34. Ge X, Yannai S, Rennert G, Gruener N, Fares FA (1996) 3,3'-Diindolylmethane induces apoptosis in human cancer cells. Biochem Biophys Res Commun 228: 153-158.

35. Ge X, Fares FA, Yannai S (1999) Induction of apoptosis in MCF-7 cells by indole-3-carbinol is independent of p53 and bax. Anticancer Res 19: 31993203.

36. Fares FA, Ge X, Yannai S, Rennert G (1998) Dietary indole derivatives induce apoptosis in human breast cancer cells. Adv Exp Med Biol 451: 153-157.

37. Cover MC, Hsieh SJ, Tran SH, Hallden G, Kim GS, et al. (1998) Indole-3carbinol inhibits the expression of cyclin-dependent kinase- 6 and induces a G1 cell cycle arrest of human breast cancer cells independent of estrogen receptor signaling. J Biol Chem 273: 3838-3847.

38. Cover CM, Hsieh SJ, Cram EJ, Hong C, Riby JE, et al. (1999) Indole-3-carbinol and tamoxifen cooperate to arrest the cell cycle of MCF-7 human breast cancer cells. Cancer Res 59: 1244-1251.

39. Cram EJ, Liu BD, Bjeldanes LF, Firestone GL (2001) Indole-3-carbinol inhibits
CDK6 expression in human MCF-7 breast cancer cells by disrupting Sp1 transcription factor interactions with a composite element in the CDK6 gene promoter. J Biol Chem 276: 22332-22340.

40. Brew CT, Aronchik I, Hsu JC, Sheen JH, Dickson RB, et al. (2006) Indole-3carbinol activates the ATM signaling pathway independent of DNA damage to stabilize p53 and induce G1 arrest of human mammary epithelial cells. Int J Cancer 118: 857-868.

41. Howells LM, Gallacher-Horley B, Houghton CE, Manson MM, Hudson EA (2002) Indole-3-carbinol inhibits proteins kinase B/Akt and induces apoptosis in the human breast tumor cell line MDA MB468 but not in the nontumorigenic HBL100 line. Mol Cancer Ther 1: 1161-1172.

42. Rahman KM, Aranha O, Sarkar FH (2003) Indole-3-carbinol (I3C) induces apoptosis in tumorigenic but not in nontumorigenic breast epithelial cells. Nutr Cancer 45: 101-112.

43. Rahman KW, Sarkar FH (2005) Inhibition of nuclear translocation of nuclear factor-\{kappa\}B contributes to 3,3'-diindolylmethane-induced apoptosis in breast cancer cells. Cancer Res 65: 364-371.

44. Meng F, Liu L, Chin PC, D'Mello SR (2002) Akt is a downstream target of NFkappa B. J Biol Chem 277: 29674-29680.

45. Grilli M, Chiu JJ, Lenardo MJ (1993) NF-kappa B and Rel: participants in a multiform transcriptional regulatory system. Int Rev Cytol 143: 1-62.

46. Karin M, Cao Y, Greten FR, Li ZW (2002) NF-kappaB in cancer: from innocent bystander to major culprit. Nat Rev Cancer 2: 301-310.

47. Li Y, Li X, Sarkar FH (2003) Gene expression profiles of I3C- and DIM-treated PC3 human prostate cancer cells determined by cDNA microarray analysis. $J$ Nutr 133: 1011-1019.

48. Fan S, Meng Q, Auborn K, Carter T, Rosen EM (2006) BRCA1 and BRCA2 as molecular targets for phytochemicals indole-3-carbinol and genistein in breast and prostate cancer cells. Br J Cancer 94: 407-426.

49. Wilson CA, Ramos L, Villaseñor MR, Anders KH, Press MF, et al. (1999) Localization of human BRCA1 and its loss in high-grade, non-inherited breast carcinomas. Nat Genet 21: 236-240.

50. Rice JC, Ozcelik H, Maxeiner P, Andrulis I, Futscher BW (2000) Methylation of the BRCA1 promoter is associated with decreased BRCA1 mRNA levels in clinical breast cancer specimens. Carcinogenesis 21: 1761-1765.

51. Moiseeva EP, Heukers R, Manson MM (2007) EGFR and Src are involved in indole-3-carbinol-induced death and cell cycle arrest of human breast cancer cells. Carcinogenesis 28: 435-445.

52. Moiseeva EP, Fox LH, Howells LM, Temple LA, Manson MM (2006) Indole-3carbinol-induced death in cancer cells involves EGFR downregulation and is exacerbated in a 3D environment. Apoptosis 11: 799-812.

53. Gong Y, Sohn H, Xue L, Firestone GL, Bjeldanes LF (2006) 3,3'-Diindolylmethane is a novel mitochondrial $\mathrm{H}(+)$-ATP synthase inhibitor that can induce p21(Cip1/ Waf1) expression by induction of oxidative stress in human breast cancer cells. Cancer Res 66: 4880-4887.

54. Scholar EM, Violi LA, Newland J, Bresnick E, Birt DF (1989) The effect of dietary fat on metastasis of the Lewis lung carcinoma and the BALB/c mammary carcinoma. Nutr Cancer 12: 109-119.

55. Bradlow HL, Michnovicz J, Telang NT, Osborne MP (1991) Effects of dietary indole-3-carbinol on estradiol metabolism and spontaneous mammary tumors in mice. Carcinogenesis 12: 1571-1574.

56. Wattenberg LW, Loub WD (1978) Inhibition of polycyclic aromatic hydrocarboninduced neoplasia by naturally occurring indoles. Cancer Res 38: 1410-1413.

57. Chen I, McDougal A, Wang F, Safe S (1998) Aryl hydrocarbon receptormediated antiestrogenic and antitumorigenic activity of diindolylmethane. Carcinogenesis 19: 1631-1639.

58. Chang X, Tou JC, Hong C, Kim HA, Riby JE, et al. (2005) 3,3'-Diindolylmethane inhibits angiogenesis and the growth of transplantable human breast carcinoma in athymic mice. Carcinogenesis 26: 771-778.

59. Wu HT, Lin SH, Chen YH (2005) Inhibition of cell proliferation and in vitro markers of angiogenesis by indole-3-carbinol, a major indole metabolite present in cruciferous vegetables. J Agric Food Chem 53: 5164-5169.

60. Rose P, Huang Q, Ong CN, Whiteman M (2005) Broccoli and watercress suppress matrix metalloproteinase-9 activity and invasiveness of human MDAMB-231 breast cancer cells. Toxicol Appl Pharmacol 209: 105-113.

61. Cookson MM (2001) Prostate cancer: screening and early detection. Cancer Control 8: 133-140. 
62. Chan JM, Giovannucci EL (2001) Dairy products, calcium, and vitamin D and risk of prostate cancer. Epidemiol Rev 23: 87-92.

63. Nupponen N, Visakorpi T (1999) Molecular biology of progression of prostate cancer. Eur Urol 35: 351-354.

64. Tang DG, Porter AT (1997) Target to apoptosis: a hopeful weapon for prostate cancer. Prostate 32: 284-293.

65. Chinni SR, Li Y, Upadhyay S, Koppolu PK, Sarkar FH (2001) Indole-3-carbinol (I3C) induced cell growth inhibition, G1 cell cycle arrest and apoptosis in prostate cancer cells. Oncogene 20: 2927-2936.

66. Chinni SR, Sarkar FH (2002) Akt inactivation is a key event in indole-3-carbinolinduced apoptosis in PC-3 cells. Clin Cancer Res 8: 1228-1236.

67. Leibelt DA, Hedstrom OR, Fischer KA, Pereira CB, Williams DE (2003) Evaluation of chronic dietary exposure to indole-3-carbinol and absorptionenhanced 3,3'-diindolylmethane in sprague-dawley rats. Toxicol Sci 74: 10-21.

68. Nachshon-Kedmi M, Yannai S, Haj A, Fares FA (2003) Indole-3-carbinol and 3,3 '-diindolylmethane induce apoptosis in human prostate cancer cells. Food Chem Toxicol 41: 745-752.

69. Nachshon-Kedmi M, Yannai S, Fares FA (2004) Induction of apoptosis in human prostate cancer cell line, PC3, by 3,3'-diindolylmethane through the mitochondrial pathway. $\mathrm{Br} \mathrm{J}$ Cancer 91: 1358-1363.

70. Wu TY, Saw CL, Khor TO, Pung D, Boyanapalli SS, et al. (2012) In vivo pharmacodynamics of indole-3-carbinol in the inhibition of prostate cancer in transgenic adenocarcinoma of mouse prostate (TRAMP) mice: involvement of Nrf2 and cell cycle/apoptosis signaling pathways. Mol Carcinog 51: 761-770.

71. Hsu JC, Zhang J, Dev A, Wing A, Bjeldanes LF, et al. (2005) Indole-3-carbinol inhibition of androgen receptor expression and downregulation of androgen responsiveness in human prostate cancer cells. Carcinogenesis 26: 18961904.

72. Le HT, Schaldach CM, Firestone GL, Bjeldanes LF (2003) Plant-derived 3,3 -Diindolylmethane is a strong androgen antagonist in human prostate cancer cells. J Biol Chem 278: 21136-21145.

73. Heath El, Heilbrun LK, Li J, Vaishampayan U, Harper F, et al. (2010) A phase I dose-escalation study of oral BR-DIM (BioResponse 3,3'- Diindolylmethane) in castrate-resistant, non-metastatic prostate cancer. Am J Transl Res 2: 402411.

74. Zhang J, Hsu B A JC, Kinseth B A MA, Bjeldanes LF, Firestone GL (2003) Indole-3-carbinol induces a G1 cell cycle arrest and inhibits prostate-specific antigen production in human $\mathrm{LNCaP}$ prostate carcinoma cells. Cancer 98: 2511-2520.

75. Aggarwal BB, Ichikawa H (2005) Molecular targets and anticancer potential of indole-3-carbinol and its derivatives. Cell Cycle 4: 1201-1215.

76. Neave AS, Sarup SM, Seidelin M, Duus F, Vang O (2005) Characterization of the N-methoxyindole-3-carbinol (NI3C)--induced cell cycle arrest in human colon cancer cell lines. Toxicol Sci 83: 126-135.

77. Garikapaty VP, Ashok BT, Chen YG, Mittelman A, latropoulos M, et al. (2005) Anti-carcinogenic and anti-metastatic properties of indole-3-carbinol in prostate cancer. Oncol Rep 13: 89-93.

78. Nachshon-Kedmi M, Fares FA, Yannai S (2004) Therapeutic activity of 3,3 '-diindolylmethane on prostate cancer in an in vivo model. Prostate 61: 153160 .

79. Li Y, Chinni SR, Sarkar FH (2005) Selective growth regulatory and pro-apoptotic effects of DIM is mediated by AKT and NF-kappaB pathways in prostate cancer cells. Front Biosci 10: 236-243.

80. Romier C, Cocchiarella F, Mantovani R, Moras D (2003) The NF-YB/NF-YC structure gives insight into DNA binding and transcription regulation by CCAAT factor NF-Y. J Biol Chem 278: 1336-1345

81. Yasui K, Okamoto H, Arii S, Inazawa J (2003) Association of over-expressed TFDP1 with progression of hepatocellular carcinomas. J Hum Genet 48: 609613

82. Garikapaty VP, Ashok BT, Tadi K, Mittelman A, Tiwari RK (2006) 3,3'-Diindolylmethane downregulates pro-survival pathway in hormone independent prostate cancer. Biochem Biophys Res Commun 340: 718-725.

83. Ahmad A, Biersack B, Li Y, Kong D, Bao B, et al. (2013) Targeted Regulation of $\mathrm{PI} 3 \mathrm{~K} / \mathrm{Akt} / \mathrm{mTOR} / \mathrm{NF}-$ ?B Signaling by Indole Compounds and their Derivatives: Mechanistic Details and Biological Implications for Cancer Therapy. Anticancer Agents Med Chem 13: 1002-1013.
84. Fresno Vara JA, Casado E, de Castro J, Cejas P, Belda-Iniesta C, et al. (2004) PI3K/Akt signalling pathway and cancer. Cancer Treat Rev 30: 193-204.

85. Jeon KI, Rih JK, Kim HJ, Lee YJ, Cho CH, et al. (2003) Pretreatment of indole3 -carbinol augments TRAIL-induced apoptosis in a prostate cancer cell line, LNCaP. FEBS Lett 544: 246-251.

86. Chen D, Banerjee S, Cui QC, Kong D, Sarkar FH, et al. (2012) Activation of AMP-activated protein kinase by 3,3'-Diindolylmethane (DIM) is associated with human prostate cancer cell death in vitro and in vivo. PLoS One 7: e47186.

87. Canene-Adams K, Lindshield BL, Wang S, Jeffery EH, Clinton SK, et al. (2007) Combinations of tomato and broccoli enhance antitumor activity in dunning r3327-h prostate adenocarcinomas. Cancer Res 67: 836-843.

88. Fares F, Azzam N, Appel B, Fares B, Stein A (2010) The potential efficacy of $3,3^{\prime}$-diindolylmethane in prevention of prostate cancer development. Eur $\mathrm{J}$ Cancer Prev 19: 199-203.

89. Bonnesen C, Eggleston IM, Hayes JD (2001) Dietary indoles and isothiocyanates that are generated from cruciferous vegetables can both stimulate apoptosis and confer protection against DNA damage in human colon cell lines. Cancer Res 61: 6120-6130.

90. Lynn A, Collins A, Fuller Z, Hillman K, Ratcliffe B (2006) Cruciferous vegetables and colo-rectal cancer. Proc Nutr Soc 65: 135-144.

91. Pappa G, Strathmann J, Löwinger M, Bartsch H, Gerhäuser C (2007) Quantitative combination effects between sulforaphane and 3,3'-diindolylmethane on proliferation of human colon cancer cells in vitro. Carcinogenesis 28: 14711477.

92. Tadi K, Chang Y, Ashok BT, Chen Y, Moscatello A, et al. (2005) 3,3'-Diidolylmethane, a cruciferous vegetable derived synthetic antiprolifereative compound in thyroid disease. Bioch Biophys Res Commun 337 1019-1025.

93. Abdelrahim M, Ewman K, Vanderlaag K, Samudio I, Safe S (2006) 3,3'-diindolylmethane (DIM) and its derivatives induce apoptosis in pancreatic cancer cells through endoplasmic reticulum stress-dependent upregulation of DR5. Carcinogenesis 27: 717-728.

94. Oganesian A, Hendricks JD, Williams DE (1997) Long term dietary indole-3carbinol inhibits diethylnitrosamine-initiated hepatocarcinogenesis in the infant mouse model. Cancer Lett 118: 87-94.

95. Qi M, Anderson AE, Chen DZ, Sun S, Auborn KJ (2005) Indole-3-carbinol prevents PTEN loss in cervical cancer in vivo. Mol Med 11: 59-63.

96. Savino JA 3rd, Evans JF, Rabinowitz D, Auborn KJ, Carter TH (2006) Multiple, disparate roles for calcium signaling in apoptosis of human prostate and cervical cancer cells exposed to diindolylmethane. Mol Cancer Ther 5: 556-563.

97. Kim DS, Jeong YM, Moon SI, Kim SY, Kwon SB, et al. (2006) Indole-3-carbino enhances ultraviolet B-induced apoptosis by sensitizing human melanoma cells. Cell Mol Life Sci 63: 2661-2668.

98. Chung FL, Morse MA, Eklind KI, Xu Y (1993) Inhibition of tobacco-specific nitrosamine-induced lung tumorigenesis by compounds derived from cruciferous vegetables and green tea. Ann N Y Acad Sci 686: 186-201.

99. Qian X, Melkamu T, Upadhyaya P, Kassie F (2011) Indole-3-carbinol inhibited tobacco smoke carcinogen-induced lung adenocarcinoma in $A / J$ mice when administered during the post-initiation or progression phase of lung tumorigenesis. Cancer Lett 311: 57-65.

100. Kim EJ, Park SY, Shin HK, Kwon DY, Surh YJ, et al. (2007) Activation of caspase-8 contributes to $3,3^{\prime}$-Diindolylmethane-induced apoptosis in colon cancer cells. J Nutr 137: 31-36.

101.Lee SH, Min KW, Zhang X, Baek SJ (2013) 3,3'-diindolylmethane induces activating transcription factor 3 (ATF3) via ATF4 in human colorectal cancer cells. J Nutr Biochem 24: 664-671.

102. Suzui M, Inamine M, Kaneshiro T, Morioka T, Yoshimi N, et al. (2005) Indole3-carbinol inhibits the growth of human colon carcinoma cells but enhances the tumor multiplicity and volume of azoxymethane-induced rat colon carcinogenesis. Int J Oncol 27: 1391-1399.

103. Bosch FX, de Sanjosé S (2003) Chapter 1: Human papillomavirus and cervical cancer--burden and assessment of causality. J Natl Cancer Inst Monogr 31 3-13.

104. Jin L, Qi M, Chen DZ, Anderson A, Yang GY, et al. (1999) Indole-3-carbinol prevents cervical cancer in human papilloma virus type 16 (HPV16) transgenic mice. Cancer Res 59: 3991-3997. 
Citation: Fares F (2014) The Anti-Carcinogenic Effect of Indole-3-Carbinol and 3, 3'-Diindolylmethane and their Mechanism of Action. Med chem S1: 002. doi:10.4172/2161-0444.S1-002

Page 8 of 8

105. Kojima T, Tanaka T, Mori H (1994) Chemoprevention of spontaneous endometrial cancer in female Donryu rats by dietary indole-3-carbinol. Cancer Res 54: 1446-1449.

106. Carter TH, Liu K, Ralph W Jr, Chen D, Qi M, et al. (2002) Diindolylmethane alters gene expression in human keratinocytes in vitro. J Nutr 132: 3314-3324

107.Sun S, Han J, Ralph WM Jr, Chandrasekaran A, Liu K, et al. (2004) Endoplasmic reticulum stress as a correlate of cytotoxicity in human tumor cells exposed to diindolylmethane in vitro. Cell Stress Chaperones 9: 76-87.

108. Kim JK, Shin EC, Kim CR, Park GG, Choi SJ, et al. (2013) Effects of brussels sprouts and their phytochemical components on oxidative stress-induced neuronal damages in PC12 cells and ICR mice. J Med Food 16: 1057-1061.

109. Reed GA, Peterson KS, Smith HJ, Gray JC, Sullivan DK, et al. (2005) A phase I study of indole-3-carbinol in women: tolerability and effects. Cancer Epidemiol Biomarkers Prev 14: 1953-1960.

110. Dalessandri KM, Firestone GL, Fitch MD, Bradlow HL, Bjeldanes LF (2004) Pilot study: effect of 3,3'-diindolylmethane supplements on urinary hormone metabolites in postmenopausal women with a history of early-stage breast cancer. Nutr Cancer 50: 161-167.

111. Naik R, Nixon S, Lopes A, Godfrey K, Hatem MH, et al. (2006) A randomized phase II trial of indole-3-carbinol in the treatment of vulvar intraepithelial neoplasia. Int J Gynecol Cancer 16: 786-790.
112. Bell MC, Crowley-Nowick $P$, Bradlow HL, Sepkovic DW, Schmidt-Grimminger D, et al. (2000) Placebo-controlled trial of indole-3-carbinol in the treatment of CIN. Gynecol Oncol 78: 123-129.

113. Wong GY, Bradlow L, Sepkovic D, Mehl S, Mailman J, et al. (1997) Doseranging study of indole-3-carbinol for breast cancer prevention. J Cell Biochem Suppl 28-29: 111-6.

114. McAlindon TE, Gulin J, Chen T, Klug T, Lahita R, et al. (2001) Indole-3-carbinol in women with SLE: effect on estrogen metabolism and disease activity. Lupus 10: $779-783$.

115. Rosen CA, Woodson GE, Thompson JW, Hengesteg AP, Bradlow HL (1998) Preliminary results of the use of indole-3-carbinol for recurrent respiratory papillomatosis. Otolaryngol Head Neck Surg 118: 810-815.

116. He YH, Friesen MD, Ruch RJ, Schut HA (2000) Indole-3-carbinol as a chemopreventive agent in 2-amino-1-methyl-6-phenylimidazo[4,5-b]pyridine (PhIP) carcinogenesis: inhibition of PhIP-DNA adduct formation, acceleration of PhIP metabolism, and induction of cytochrome P450 in female F344 rats. Food Chem Toxicol 38: 15-23.

117. Lake BG, Tredger JM, Renwick AB, Barton PT, Price RJ (1998) 3,3'-Diindolylmethane induces CYP1A2 in cultured precision-cut human liver slices. Xenobiotica 28: 803-811. 